\title{
Article \\ A Unique Model to Estimate Geometric Deviations in Drilling and Milling Due to Two Uncertainty Sources
}

\author{
Wilma Polini *(D) and Andrea Corrado \\ Department of Civil and Mechanical Engineering, Università degli Studi di Cassino e del Lazio Meridionale, \\ via G. di Biasio 43, 03043 Cassino, Italy; a.corrado@unicas.it \\ * Correspondence: polini@unicas.it; Tel.: +39-0776-299-3679
}

Citation: Polini, W.; Corrado, A. A Unique Model to Estimate Geometric Deviations in Drilling and Milling Due to Two Uncertainty Sources. Appl. Sci. 2021, 11, 1996 https://doi.org/10.3390/ app11051996

Academic Editors: José A.F.O. Correia and Kang Su Kim

Received: 31 January 2021

Accepted: 19 February 2021

Published: 24 February 2021

Publisher's Note: MDPI stays neutral with regard to jurisdictional claims in published maps and institutional affiliations.

Copyright: (c) 2021 by the authors. Licensee MDPI, Basel, Switzerland. This article is an open access article distributed under the terms and conditions of the Creative Commons Attribution (CC BY) license (https:// creativecommons.org/licenses/by/ $4.0 /)$.

\begin{abstract}
Industry 4.0 involves the use of information and communication technologies to transform industry by intelligent networking machines and processes. The availability of big data sets from manufacturing and inspection allow for developing new and more accurate simulation models. This involves the development of new machining simulation models to consider the geometrical deviations of the workpiece due to the machine tool, the part datum surfaces and the fixturing equipment. This work presents a model that kinematically correlates the locator uncertainty, the form deviation on the part datum surface in contact with the locators and the volumetric uncertainty of the machine tool, with the geometric deviations of a surface due to a drilling or milling process. An analytical model was developed in a Matlab ${ }^{\circledR}$ file to simulate the surface geometrical deviations from nominal during drilling or milling. It is new as regards the state of the art because it takes into account two sources of uncertainty. This numerical approach allows for avoiding experimental tests, with a resultant saving of time, energy and material. It was applied to drilling, face milling and contouring processes. It was proved that machine tool volumetric uncertainty influences the form deviation of the machined surface, while the locator configuration and the datum form deviation affect the orientation of the machined surface, as should be in reality. The proposed model allows us to take into account geometrical deviations of the part datum surfaces of $0.001 \mathrm{~mm}$, location deviations in the locators of $\pm 0.03 \mathrm{~mm}$ and machine tool positional and rotational uncertainties of $0.01 \mathrm{~mm}$ and $\sigma_{d}=0.01 * \frac{\pi}{180} \mathrm{~mm}$, respectively.
\end{abstract}

Keywords: uncertainty model; uncertainty separation; machining accuracy; locators; machine tool volumetric uncertainty

\section{Introduction}

Machining processes are still widely used because they remain capable of producing workpieces characterized by a great geometric accuracy. However, high-value applications require controlling the quality and the manufacturing signature of the products carefully because they affect their performances in practice [1,2]. Achieving this aim is not so easy. Surface roughness is the most industrially used indicator to describe surface quality, but an indicator of surface geometrical deviation, such as flatness and orientation, must be added to it [3]. In fact, surface integrity involves macro-geometrical deviations (dimensional and geometrical) and micro-geometrical deviations (roughness profile), as well as some physicochemical properties of the machined surface [4]

At the same time, having a model to foresee the deviations in geometry, the surface quality and the surface morphology of a manufactured part is very useful for production engineers. In fact, they commonly choose the machine and the manufacturing parameters based on their experience by choosing over-simplified approaches. However, another phenomenon is present in many manufacturing processes, defects from previous technological operations that are transferred to the final product, which is known as technological heredity [5]. It affects product surface quality and its geometrical deviations. 
It is possible to draw an uncertainty budget of all the elements that affect the accuracy of the workpiece, i.e., the machine, the process, the auxiliary equipment and the interactions between them, by means of the method outlined by Slocum [6]. The machine uncertainty is connected with machine construction uncertainty, uncertainty due to the wear of the parts and uncertainty due to the control of each drive unit [7]. The process uncertainty is due to tool deflection, tool wear, vibration, thermal distortions and burr formation [8]. An interesting model on process uncertainty was developed in [9]; it describes the relationship of the flatness of a milled surface with cutting force and tool wear. The same authors [10] studied the use of different machine learning techniques to predict flatness in face milling operations. Therefore, there is uncertainty originating in workpiece positioning that is related to the contact points between the locators and the workpiece surface, and it is known as localization uncertainty [11] or datum establishment uncertainty [12]. The localization uncertainty depends on the deviation of the locators from their nominal position and the form deviation of the surface in contact with the locators. It is needed to find the locator position that reduces it [13], i.e., it is needed to optimize fixture layout.

Many studies of the literature focused on the influence of the fixture on the part deviation [14]. The part deviation due to the geometric variation of the part-holder was modelled through the small displacement torsor concept [15]. The displacement screw vector was used to describe mathematically the localization error [16]. The localization error of a critical feature was minimized through optimization techniques [17]. The geometric deviations of the workpiece datum surfaces were combined with the worst-case locator error in machined features [18]. They take into account the manufacturing deviations of the workpiece datums inside location, profile and angular tolerances. Fixture layout design techniques were used to reduce the localization error of turbine air foils [19]. A robust approach to fixture layout in prismatic workpieces was resolved through genetic algorithms [20].

Moreover, the literature presents intensive research on error modeling of machine tools. A quadratic model of the machine volumetric error was presented [21], in which each axis was considered separately. A Jacobian model was used for machine tool error by dividing the compensable ones from those not compensable [22]. A comprehensive error analysis method was proposed for a multi-axis machine tool; it evaluates the geometric error propagation through every motion axis and which error parameter has greater influence on the tool position error at the end of the kinematic chain [23]. A geometric error model based on stream of variation theory [24] or non-uniform rational B-spline [25] was proposed for a multi-axis machine too. An experimental approach to evaluate component stiffness in a turning center was developed in [26]. Some papers of the literature discuss the way to compensate the volumetric error of a machine tool [27-29].

This paper presents an innovative model as regards the literature by considering localization and machine uncertainty. Its aim is to present a model to combine the uncertainty of a machined surface with two sources of uncertainty: the localization and the machine ones. The developed model is a kinematic chain of geometrical deviations from the nominal workpiece position and orientation to the new ones due to locator uncertainty and then to these due to workpiece datum surface flatness to which the machine tool volumetric uncertainty is added.

Previous papers presented a statistical model to foresee the position deviation of a hole or a hole pattern dependent on the inaccurate positions of the six locators of the 3-2-1 locating scheme [30,31]. Then a further model was developed by putting together the deviations in locator positions with the volumetric uncertainty of the machine tool [32] or with the form deviation in workpiece datum surfaces [33].

The aim of the present paper is to show a kinematic model developed for drilling and milling processes. It correlates the locator uncertainty, the form deviation on the part datum surface in contact with the locators and the volumetric uncertainty of the machine tool with the form and/or the orientation of a machined surface during drilling, facing or contouring operations. An alternative experimental approach would have required many 
tests planned through design of experimental techniques to delineate the surface form and orientation deviation trend as a function of the abovementioned parameters. In this case, an analytical approach was developed to simulate surface geometric deviations from nominal during milling or drilling. The model, that was developed in a Matlab ${ }^{\circledR}$ file, takes into account the deviation of the part reference frame connected with locator uncertainty and datum form deviation to which the volumetric uncertainty of a machine tool was added. This way allows avoiding wasting time, energy and materials for experimental tests to evaluate the parameters influencing machined surfaces.

In Section 2, the model is theoretically presented and mathematically described. In Section 3, the model is applied to drilling, facing and contouring processes by considering two different configurations of the locators. The obtained results are deeply discussed.

\section{Materials and Methods}

The nominal surface obtained through a drilling or a milling process is represented by a set of points that is its skin model. The geometric uncertainty of a drilling or a milling operation refers to the deviation between the location of the points belonging to the actual machined surface and that of the nominal one. The developed model combines this deviation with the inaccuracy of the locator configuration, the workpiece and the machine tool.

The position and orientation of the workpiece reference frame with respect to the machine one is due to the machining fixture that is constituted by reference elements, i.e., the locators. The six-point or 3-2-1 scheme is the most common locator scheme, i.e., six locators identify three mutually orthogonal datum reference planes (i.e., the workpiece reference frame). The tool path is defined with respect to this workpiece reference frame. The workpiece reference frame deviates from nominal because the geometry and the position of the locators are not nominal; this misalignment induces geometrical deviations from nominal of machined features, such as flatness of a milled surface or an orientation uncertainty of a milled surface and drilled hole. It was chosen to investigate these kinds of geometric deviations because they are more influenced by the uncertainty sources that are taken into account. The six locators have eighteen coordinates that define their position, of which only six significantly influence the machining uncertainty, as demonstrated in [30]. The locators' coordinates are assumed following a probability density function and the related locator reference frame is defined.

The workpiece to machine is geometrically perfect nominally. However, it is actually obtained through a manufacturing process that leaves on its boundary surfaces a manufacturing signature [34-36]. This paper considers a simultaneous autoregressive model of first order SAR(1) to simulate the signature on the planes in contact with the 3-2-1 locators [37]. The SAR(1) model is suitable to simulate spatially correlated phenomena and deviations in a finite number of points. A set of evenly distributed points was used to simulate the three planes in contact with the six locators. The six points of the three datum planes nearest to the generic set of locators define the workpiece reference frame.

A machine tool is a chain of translational and/or rotational kinematic components. Therefore, the geometric deviations of each component may be modeled by means of a transformation matrix and the machine tool's resulting uncertainty is obtained by multiplying the transformation matrices in the order of the kinematic chain. The proposed model is kinematic and it is based on the results sought in the kinematics of robots that are validated in the literature [38].

Three locators on the primary datum, two on the secondary and one on the tertiary determine the workpiece position (see Figure 1). The coordinates of the i-th locator are represented by $\mathbf{p}_{\mathbf{i}}\left(\mathrm{x}_{\mathrm{i}}, \mathrm{y}_{\mathrm{i}}, \mathrm{z}_{\mathrm{i}}\right)$. The model's aim is to estimate the actual coordinates of the points belonging to the machined surface in the workpiece reference frame. It takes as input the dimensions of the workpiece, the nominal locator configuration, the diameter of the cutter and the number and nominal coordinates of the points on the machined surface. 


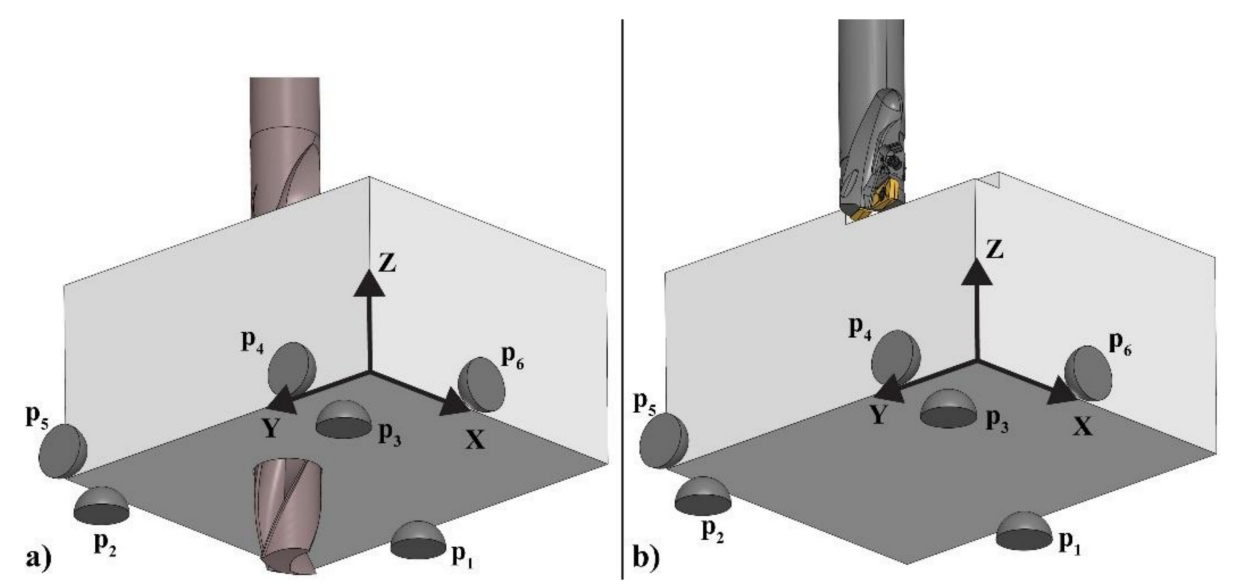

Figure 1. The 3-2-1 locator scheme for: (a) drilling; (b) milling.

\subsection{Locator Deviations}

The position of the six locators is completely defined by six of the eighteen coordinates, as demonstrated in [29]. Each of these six coordinates is assumed to be affected by an uncertainty behaving independently, according to a Gaussian $N\left(0, \sigma^{2}\right)$ distribution.

The locator reference frame (LRF) is identified by the straight line (i.e., $Z^{\prime}$ axis) perpendicular to the plane passing through the actual positions of locators $\mathbf{p}_{1}, \mathbf{p}_{\mathbf{2}}$ and $\mathbf{p}_{3}$, the straight line (i.e., $Y^{\prime}$ axis) that passes through the locators $\mathbf{p}_{4}$ and $\mathbf{p}_{5}$ and is perpendicular to the $Z^{\prime}$ axis and the perpendicular line to both $Z^{\prime}$ and $Y^{\prime}$ axes, that is, the $X^{\prime}$ axis, passing from the $\mathbf{p}_{6}$ locator.

The nominal coordinates of the $\mathrm{i}$-th point on the machined surface are $\mathbf{P}_{\mathbf{i}}\left(\mathrm{x}_{\mathrm{i}}, \mathrm{y}_{\mathrm{i}}, \mathrm{z}_{\mathrm{i}}\right)$, while their real values $\mathbf{P}_{\mathbf{i}}{ }^{\prime}\left(\mathrm{x}_{\mathrm{i}}{ }^{\prime}, \mathrm{y}_{\mathrm{i}}{ }^{\prime}, \mathrm{z}_{\mathrm{i}}{ }^{\prime}\right)$ are a function of locator probability density functions in the locator reference frame (LRF). It is possible to find the real coordinates $\mathbf{P}_{\mathbf{i}}{ }^{\prime}\left(\mathrm{x}_{\mathrm{i}}{ }^{\prime}, \mathrm{y}_{\mathrm{i}}{ }^{\prime}, \mathrm{z}_{\mathrm{i}}{ }^{\prime}\right)$ by the nominal ones $\mathbf{P}_{\mathbf{i}}\left(\mathrm{x}_{\mathrm{i}}, \mathrm{y}_{\mathrm{i}}, \mathrm{z}_{\mathrm{i}}\right)$ through a homogeneous transformation matrix ${ }^{0} R_{p}^{-}$:

$$
\mathbf{P}_{\mathbf{i}}^{\prime}={ }^{0} R_{p}^{-} * \mathbf{P}_{\mathbf{i}}=\left[\begin{array}{cc}
\mathbf{R} & \mathbf{t}_{\mathbf{i}} \\
\mathbf{o}^{\mathbf{T}} & 1
\end{array}\right] * \mathbf{P}_{\mathbf{i}},
$$

where $\mathbf{R}$ is the rotational matrix which allows passing by the nominal locator reference frame $\left(\mathrm{LRF}_{\mathrm{n}}\right)$ to the perturbed locator reference frame (LRF) as a function of locator position inaccuracies, $t_{0}$ is the vector describing the $L R F_{n}$ origin position referring to the $L R F$ and $\mathbf{o}^{\mathbf{T}}$ is a zero vector $[3 \times 1]$. In detail

$$
\begin{gathered}
\mathbf{R}=\left|\begin{array}{c}
\mathbf{n}_{\mathbf{x}}^{\mathrm{T}} \\
\mathbf{n}_{\mathbf{y}}^{\mathrm{T}} \\
\mathbf{n}_{\mathbf{z}}^{\mathrm{T}}
\end{array}\right|, \\
\mathbf{n}_{\mathbf{x}}=\frac{\mathbf{v}_{2}}{\left\|\mathbf{v}_{2}\right\|}=\frac{\mathbf{p}_{45} * \mathbf{v}_{1}}{\left\|\mathbf{p}_{45} * \mathbf{v}_{1}\right\|}, \\
\mathbf{p}_{45}=\mathbf{p}_{5}-\mathbf{p}_{4}, \\
n_{y}=\frac{\mathbf{v}_{3}}{\left\|\mathbf{v}_{3}\right\|}=\frac{\mathbf{v}_{1} * \mathbf{v}_{2}}{\left\|\mathbf{v}_{1} * \mathbf{v}_{2}\right\|}, \\
n_{z}=\frac{\mathbf{v}_{1}}{\left\|\mathbf{v}_{1}\right\|}=\frac{\mathbf{p}_{13} * \mathbf{p}_{12}}{\left\|\mathbf{p}_{13} * \mathbf{p}_{12}\right\|}, \\
\mathbf{p}_{13}=\mathbf{p}_{3}-\mathbf{p}_{1}, \\
\mathbf{p}_{12}=\mathbf{p}_{2}-\mathbf{p}_{1},
\end{gathered}
$$




$$
\mathbf{t}_{\mathbf{i}}=\left|\begin{array}{c}
\mathbf{n}_{\mathrm{x}}^{\mathrm{T}} * \mathbf{p}_{4} \\
\mathbf{n}_{\mathrm{y}}^{\mathrm{T}} * \mathbf{p}_{6} \\
\mathbf{n}_{\mathbf{z}}^{\mathrm{T}} * \mathbf{p}_{1}
\end{array}\right|,
$$

\subsection{Datum Form Deviations}

The form deviation or the manufacturing signature (d) of the datum surface in contact with the locators was simulated through a spatial autoregressive (SAR) model [37]:

$$
\mathbf{d}=(\mathbf{I}-\rho \mathbf{W})^{-1} \mathbf{\epsilon},
$$

with $\mathbf{W}$ being a spatial weighting matrix of an observed variable, $\rho$ a spatial autoregressive parameter whose value is 0.9 in order to have a high correlation among the points on the plane, I the identity matrix and $\epsilon \sim\left(0, \sigma^{2} \mathbf{I}\right)$ the white noise. $\mathbf{W}$ is a neighborhood matrix defined based on the triangulation of the points on the plate surface:

$$
\mathrm{w}_{\mathrm{lj}}=\frac{\frac{\mathrm{I}_{\mathrm{lj}}}{\mathrm{d}_{\mathrm{lj}}}}{\sum_{\mathrm{k}} \frac{\mathrm{I}_{\mathrm{kj}}}{\mathrm{d}_{\mathrm{kj}}}},
$$

with $d_{l j}$ being the Cartesian distance between the $\mathbf{P}_{\mathbf{l}}$ and the $\mathbf{P}_{\mathbf{j}}$ points of the surface, and $\mathrm{I}_{\mathrm{lj}}$ is an indicator variable, which denotes whether points $l$ and $j$ are neighbors, that is

$$
\mathrm{I}_{\mathrm{lj}}=\left\{\begin{array}{c}
1, \text { if point } l \text { and } j \text { belong to a same triangle } \\
0, \text { otherwise }
\end{array},\right.
$$

Given a set of samples $\left\{\left(x_{i}, y_{i}, z_{i}\right)\right\}_{i=1}^{m}$ from Equation (10) to represent the three surfaces of the workpiece in contact with the 3-2-1 locators, it is necessary to determine a set of six points, $\mathbf{A}, \mathbf{B}, \mathbf{C}, \mathbf{D}, \mathbf{E}, \mathbf{F}$ at the minimum distance from the $\mathbf{p}_{1}, \mathbf{p}_{2}, \mathbf{p}_{3}, \mathbf{p}_{4}, \mathbf{p}_{5}$ and $\mathbf{p}_{6}$ locators.

Then, it is possible to express the coordinates of the points $\mathbf{P}_{\mathrm{i}}{ }^{\prime}\left(\mathrm{x}_{\mathrm{i}}{ }^{\prime}, \mathrm{y}_{\mathrm{i}}{ }^{\prime}, \mathrm{z}_{\mathrm{i}}{ }^{\prime}\right)$ of the machined surface from the locator reference frame (LRF) to the part reference frame (PRF):

$$
\mathbf{P}_{\mathbf{i}}^{\prime \prime}={ }^{1} \mathbf{R}_{\mathbf{p}}^{-2} * \mathbf{P}_{\mathbf{i}}^{\prime}=\left|\begin{array}{cc}
\mathbf{R}^{\prime} & \mathbf{t}_{\mathbf{i}}^{\prime} \\
\mathbf{o}^{\mathbf{T}} & 1
\end{array}\right| * \mathbf{P}_{\mathbf{i}}^{\prime \prime}
$$

with $\mathbf{R}^{\prime}$ is the rotational matrix which allows passing by the LRF to PRF, while $\mathbf{t}_{\mathbf{i}}{ }^{\prime}$ is the vector describing the LRF origin position referring to the PRF and $\mathbf{o}^{\mathbf{T}}$ is a zero vector [3×1]. In detail

$$
\begin{aligned}
& \mathbf{R} \prime=\left|\begin{array}{c}
\mathbf{n}_{\mathbf{x}}^{\mathrm{T}} \\
\mathbf{n}_{\mathrm{y}}^{\mathrm{T}} \prime \\
\mathbf{n}_{\mathbf{z}}^{\mathrm{T}}{ }^{\mathrm{T}}
\end{array}\right|, \\
& \mathbf{n}_{\mathbf{x}}{ }^{\prime}=\frac{\mathbf{v}_{2}{ }^{\prime}}{\left\|\mathbf{v}_{2}^{\prime}\right\|}=\frac{D^{\prime} E^{\prime} * \mathbf{v}_{1^{\prime}}}{\left\|D^{\prime} E^{\prime} * \mathbf{v}_{1^{\prime}}\right\|},
\end{aligned}
$$

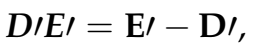

$$
\begin{aligned}
& \mathbf{D}^{\prime}={ }^{0} \mathbf{R}_{\mathbf{p}}^{-1} * \mathbf{D} \text { ， } \\
& \mathbf{E}^{\prime}={ }^{0} \mathbf{R}_{\mathbf{p}}^{-1} * \mathbf{E}, \\
& \mathbf{F}^{\prime}={ }^{0} \mathbf{R}_{\mathbf{p}}^{-1} * \mathbf{F}, \\
& n_{y}=\frac{\mathbf{v}_{3} \prime}{\left\|\mathbf{v}_{3}\right\|}=\frac{\mathbf{v}_{1^{\prime}} * \mathbf{v}_{2} \prime}{\left\|\mathbf{v}_{1} \prime * \mathbf{v}_{2} \prime\right\|}, \\
& \boldsymbol{n}_{z}=\frac{\mathbf{v}_{1}^{\prime}}{\left\|\mathbf{v}_{1}^{\prime}\right\|}=\frac{A^{\prime} C^{\prime} * A^{\prime} B^{\prime}}{\left\|A^{\prime} C^{\prime} * A^{\prime} B^{\prime}\right\|},
\end{aligned}
$$




$$
\begin{aligned}
& A \prime C^{\prime}=\mathbf{C}^{\prime}-\mathbf{A} \prime \\
& A^{\prime} \mathbf{B}^{\prime}=\mathbf{B}^{\prime}-\mathbf{A} \prime \\
& \mathbf{A}^{\prime}={ }^{0} \mathbf{R}_{\mathbf{p}}^{-1} * \mathbf{A} \\
& \mathbf{B}^{\prime}={ }^{0} \mathbf{R}_{\mathbf{p}}^{-1} * \mathbf{B} \\
& \mathbf{C}^{\prime}={ }^{0} \mathbf{R}_{\mathbf{p}}^{-1} * \mathbf{C} \\
& \mathbf{t}_{\mathbf{i}}{ }^{\prime}=\left|\begin{array}{c}
\mathbf{n}_{\mathbf{x}}^{\mathrm{T}} * \mathbf{D} \prime \\
\mathbf{n}_{\mathbf{y}}^{\mathrm{T}} * \mathbf{F} \prime \\
\mathbf{n}_{\mathbf{z}}^{\mathbf{T}} * \mathbf{A} \prime
\end{array}\right|
\end{aligned}
$$

\subsection{Machine Tool Volumetric Uncertainty}

The machine tool volumetric uncertainty is described through the position uncertainty $\Delta p$ of the tool tip in the machine tool reference system, and the direction uncertainty $\Delta d$ of the tool axis. It is possible to estimate $\Delta p$ and $\Delta d$ as:

$$
\left[\begin{array}{c}
\Delta_{\mathrm{p}} \\
\Delta_{\mathrm{d}}
\end{array}\right]=\left[\begin{array}{cccccc}
1 & 1 & 1 & 0 & 0 & 0 \ldots \\
0 & 0 & 0 & 0 & 0 & 0 \ldots \\
z-l & z-l & -l & -y & 0 & 0 \\
0 & 0 & 0 & 1 & 1 & 1 \ldots \\
0 & 0 & 0 & l-z & l-z & 1 \ldots \\
0 & 0 & 0 & 0 & 0 & 0 \\
0 & 0 & 0 & 0 & 0 & 0 \ldots \\
1 & 1 & 1 & 0 & 0 & 0 \ldots \\
0 & 0 & 0 & 0 & 0 & 0 \\
0 & 0 & 0 & 0 & 0 & 0 \ldots \\
0 & 0 & 0 & 1 & 0 & 0 \ldots \\
-1 & -1 & -1 & 0 & 0 & 0 \\
0 & 0 & 0 & 0 & 0 & 0 \ldots \\
0 & 0 & 0 & 1 & 1 & 1 \ldots \\
0 & 1 & 0 & 0 & 0 & 0 \\
0 & 0 & 0 & 0 & 0 & 0 \ldots \\
0 & 0 & 0 & 0 & 0 & 0 \ldots \\
0 & 0 & 0 & 0 & 0 & 1
\end{array}\right]\left[\begin{array}{c}
\delta_{x}(\mathrm{x}) \\
\delta_{x}(y) \\
\delta_{x}(z) \\
\delta_{y}(x) \\
\delta_{y}(y) \\
\delta_{y}(z) \\
\delta_{z}(x) \\
\delta_{z}(y) \\
\delta_{z}(z) \\
\varepsilon_{x}(x) \\
\varepsilon_{x}(y) \\
\epsilon_{x}(z) \\
\varepsilon_{y}(x) \\
\varepsilon_{y}(y) \\
\varepsilon_{y}(z) \\
\varepsilon_{z}(x) \\
\varepsilon_{z}(y) \\
\varepsilon_{z}(z)
\end{array}\right]=\mathrm{gd}
$$

with $\delta$ and $\varepsilon$ the translation and rotation uncertainties along and around the $x, y$ and $z$ axes (e.g., $\varepsilon_{z}(\mathrm{x})$ is the rotational uncertainty around the $z$ axis due to a translation along the $x$ axis). They are independently distributed as a Gaussian $N\left(0, \sigma_{p}^{2}\right)$ or $N\left(0, \sigma_{d}^{2}\right)$ distribution, respectively. The vector $\left[\begin{array}{c}\Delta_{p} \\ \Delta_{d}\end{array}\right]$ follows a multivariate Gaussian distribution, with a null expected value and covariance matrix which can be calculated by the formula $G \Sigma \mathbf{G}^{\mathrm{T}}$, where $\Sigma$ is the covariance matrix of d. $\Sigma$ is a diagonal $18 \times 18$ matrix with the first nine diagonal elements equal to $\sigma_{p}^{2}$ and the remaining diagonal elements equal to $\sigma_{d}^{2}$.

This model was used to simulate the uncertainty in the location and direction of the points belonging to the machined surface due to the machine tool volumetric uncertainty. 


\subsection{Milled Surface}

The coordinates of the $\mathrm{i}$-th point on the milled surface in the part reference frame (PRF) are obtained through the kinematic chain from its coordinates in the nominal locator reference frame $\left(\mathrm{LRF}_{\mathrm{n}}\right)$ to those in the locator reference frame (LRF) and from the latter to those in the part reference frame (PRF). To the coordinates in the PRF were added the volumetric uncertainty of the machine tool to arrive at the coordinates of the i-th point of the milled top surface in the PRF. Equation (16) becomes:

$$
\mathbf{P}_{\mathbf{i}}^{\prime \prime}={ }^{1} \mathbf{R}_{\mathbf{p}}^{-2}\left[{ }^{0} \mathbf{R}_{\mathbf{p}}^{-1}\left(\mathbf{P}_{\mathbf{i}}+\Delta_{\mathbf{p}}\right)\right]
$$

The mill tool direction in the PRF is given by

$$
\mathbf{k}^{\prime \prime}={ }^{1} \mathbf{R}_{\mathbf{p}}^{-2}\left[{ }^{0} \mathbf{R}_{\mathbf{p}}^{-1}\left(\mathbf{k}+\Delta_{\mathbf{d}}\right)\right]
$$

with $\mathbf{k}$ being the direction of the mill tool in the machine tool reference frame.

The i-th point $\mathbf{P}_{\mathbf{i}}^{\prime \prime \prime}$ on the milled surface is given by the following relationship:

$$
\mathbf{P}_{\mathbf{i}}^{\prime \prime \prime}=\mathbf{P}_{\mathbf{i}}^{\prime \prime}+l \mathbf{k}^{\prime \prime}
$$

where $l$ is the cutting depth.

The flatness was determined by the sum of the distances of the two points more distant from the plane obtained by the method of least squares:

$$
\Delta=\delta_{\max }+\left|\delta_{\min }\right|
$$

The angle between the top and bottom planes was determined as the opposite angle to the normal of two planes:

$$
\Phi=180^{\circ}-\arccos \left(\frac{u_{1} \cdot u_{2}}{\left\|u_{1}\right\|\left\|u_{2}\right\|}\right)
$$

\subsection{Drilled Surface}

From the model detailed in the previous paragraphs, it is possible to define the axis of the drilled hole through Point $\mathbf{P}_{\mathbf{0}}$ " and vector $\mathbf{k}^{\prime \prime}$ :

$$
\begin{aligned}
\mathbf{P}_{0}^{\prime \prime} & ={ }^{1} \mathbf{R}_{\mathbf{p}}^{-2}\left[{ }^{0} \mathbf{R}_{\mathbf{p}}^{-1}\left(\mathbf{P}_{0}+\Delta_{\mathbf{p}}\right)\right] \\
\mathbf{k}^{\prime \prime} & ={ }^{1} \mathbf{R}_{\mathbf{p}}^{-2}\left[{ }^{0} \mathbf{R}_{\mathbf{p}}^{-1}\left(\mathbf{k}+\Delta_{\mathbf{d}}\right)\right]
\end{aligned}
$$

A point belonging to the axis is $\mathbf{p}^{\prime \prime}$ with $s \in \mathrm{R}$ :

$$
\mathbf{p}^{\prime \prime}=\mathbf{P}_{0}^{\prime \prime}+s \mathbf{k}^{\prime \prime}
$$

Therefore, the distances between the exit and entrance points of the drilled and nominal holes are given by:

$$
\begin{aligned}
& d_{1}=\left|\mathbf{P}_{0}^{\prime \prime}+s_{\text {entrance }} \mathbf{k}^{\prime \prime}-\mathbf{P}_{0}\right| \\
& d_{2}=\left|\mathbf{P}_{0}^{\prime \prime}+s_{\text {exit }} \mathbf{k}^{\prime \prime}-\mathbf{P}_{0, \mathbf{e x i t}}\right|
\end{aligned}
$$

with $\mathbf{P}_{\mathbf{0}, \text { exit }}$ being the nominal coordinates of hole exit point.

\section{Results}

The model was applied to a plate of $100 \mathrm{~mm} \times 120 \mathrm{~mm}$ and a thickness of $60 \mathrm{~mm}$. The locators were placed according to a Gaussian probability density function, centered 
on the nominal position and characterized by a standard deviation $\sigma=0.01 \mathrm{~mm}$. The locators' nominal positions were $\mathbf{p}_{\mathbf{1}}(95,70,0), \mathbf{p}_{\mathbf{2}}(12.5,117.63,0), \mathbf{p}_{\mathbf{3}}(12.5,22.37,0), \mathbf{p}_{\mathbf{4}}(0,25$, $5), \mathbf{p}_{5}(0,115,5), \mathbf{p}_{6}(40,0,5)$ in the first case study, to have the three locators at the bottom surface barycentric, i.e., the barycenter among the locators' positions is the hole position, and at the maximum distance, i.e., the workpiece surface included inside the three locators is maximum, the two lateral locators at the maximum distance and the sixth locator on the hole axis, as shown in Figure $2 \mathrm{a}$, and $\mathbf{p}_{\mathbf{1}}(95,60,0), \mathbf{p}_{\mathbf{2}}(5,111.96,0), \mathbf{p}_{\mathbf{3}}(5,8.04,0), \mathbf{p}_{4}(0$, $5,5), \mathbf{p}_{5}(0,115,5), \mathbf{p}_{6}(95,0,5)$ for the second case study, to have the three locators at the bottom surface at the maximum area, the two lateral locators at the maximum distance and the sixth locator at the maximum distance from the origin, as shown in Figure $2 \mathrm{~b}$. The positioning and rotational uncertainties characterizing the machine tool volumetric uncertainty are equal to $\sigma_{p}=0.01 \mathrm{~mm}$ and $\sigma_{d}=0.01 * \frac{\pi}{180} \mathrm{~mm}$, respectively. The SAR model is characterized by a white noise $\epsilon \sim\left(0, \sigma^{2} \mathbf{I}\right)$ with $\sigma=0.01 \mathrm{~mm}$, and a spatial autoregressive parameter $\rho=0.9$. The points on the datum surfaces were simulated with a deviation along a direction perpendicular to the datum that was randomly distributed from a uniform probability density function with $\sigma=0.001 \mathrm{~mm}$. The limits of the simulated uncertainty were taken from a study of the literature on the locating equipment, the machine tools and the geometric dimensioning and tolerancing (GD\&T) [24].
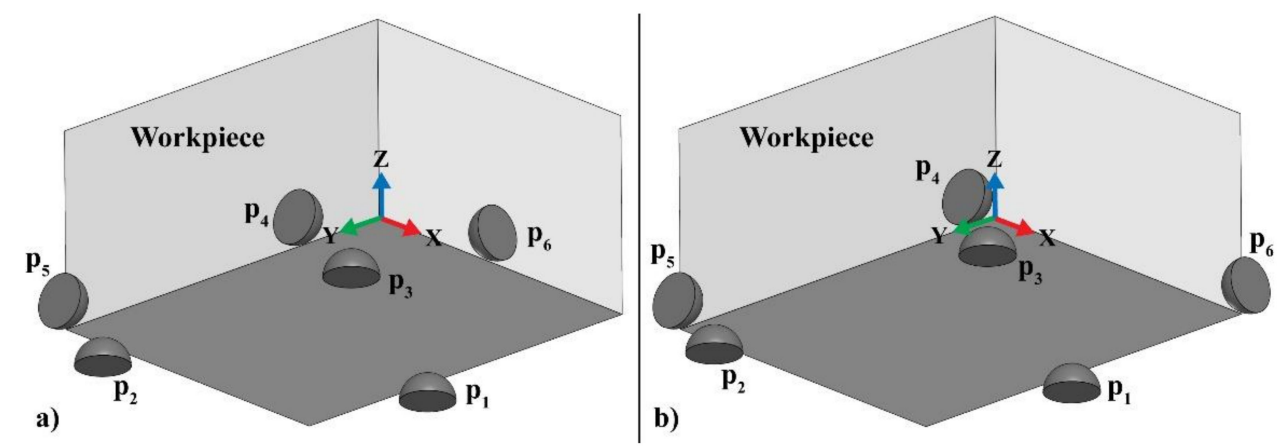

Figure 2. First (a) and second (b) configuration of the locators.

\subsection{Face Milling}

The plate was milled with a depth of cut of $30 \mathrm{~mm}$ in order to remove all the stock through a single pass. An end mill of $20 \mathrm{~mm}$ in diameter was used in order to increase the number of control points on the milled surface. The rigidity of the mill was not considered, because the model does not take into account the process uncertainty. The plane to be milled was represented by a set of 3D points, the points were arranged in a grid along the two $x-y$ directions and the distance between two consecutive points was equal to the nominal radius of the cutter along each of the two $x-y$ directions (see Figure 3a); thus, a matrix of $\mathrm{m} \times \mathrm{n}$ 3D points represented the skin model of the nominal plane (see Figure $3 \mathrm{~b}$ ). The coordinates of each point belonging to the milled surface in the workpiece reference frame (WRF) were estimated starting from the coordinates in the machine reference frame (MRF) and switching to the locator reference frame (LRF) and then to the workpiece reference frame through the laws of robot kinematics, as shown in Figure 4. In fact, Figure 4 shows the geometrical deviation of a milled surface due to the synergic effect of locators, flatness of datum surface and machine tool volumetric uncertainty. Finally, the machine tool uncertainty was added to the coordinates of each point in the WRF to obtain the points on the actual milled surface. The random shape of the milled surface can be observed (green in Figure 4) due to the random uncertainty of the machine tool. 


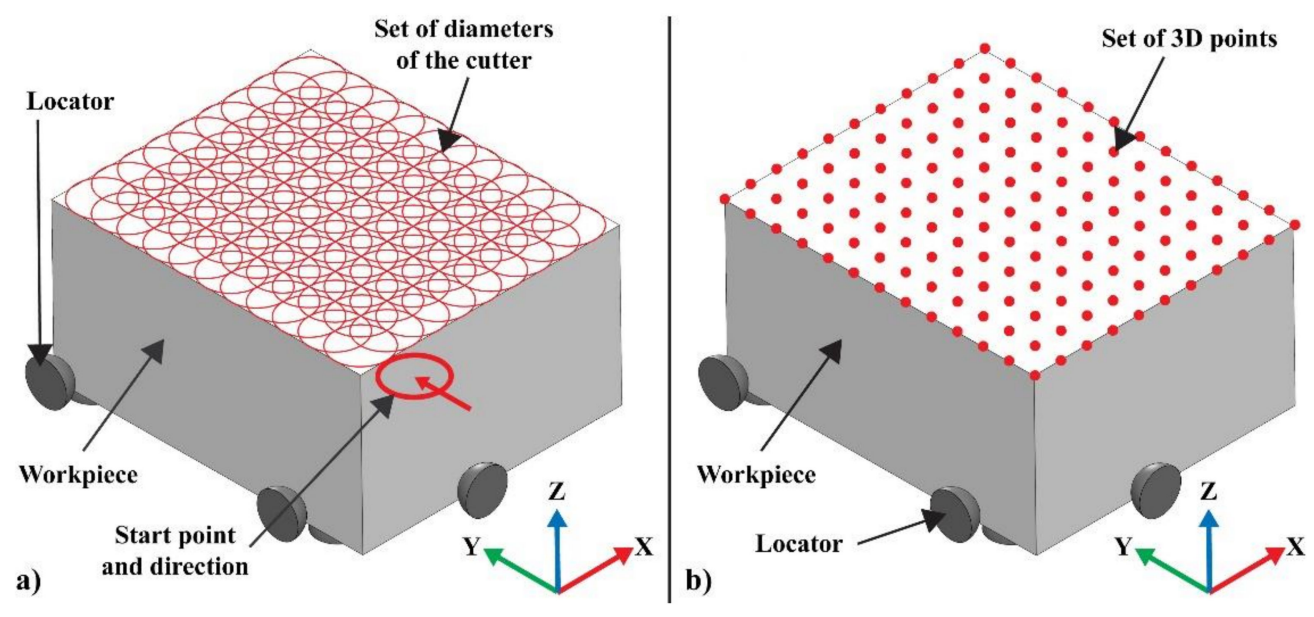

Figure 3. (a) Set of diameters of the cutter during the milling, (b) skin model shape of a milled plane.

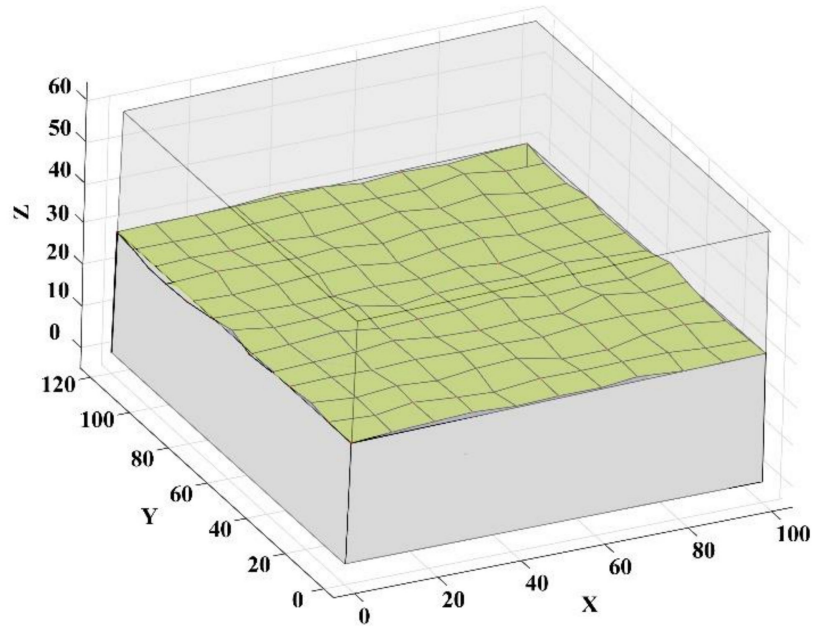

Figure 4. Simulated milled surface (uncertainty amplified 30 times).

The least squares method was applied to the coordinates of the points on the actual milled surface to obtain an approximate plane. The flatness was determined by the sum of the distances from the least squares plane of the two points that are the most distant. To evaluate the deviation of the milled surface orientation, the angle between the normals of the top and bottom planes was calculated.

Figure 5 shows the results of numerical simulations obtained for each of the two considered sources of uncertainty and all their combinations $(\mathrm{L}=$ locator uncertainty, $\mathrm{M}=$ volumetric uncertainty of machine tool, $\mathrm{F}=$ datum flatness, $\mathrm{L}+\mathrm{M}=$ locator + volumetric uncertainty, $\mathrm{L}+\mathrm{F}=$ locator + datum flatness, $\mathrm{F}+\mathrm{M}=$ datum flatness + volumetric uncertainty, $\mathrm{L}+\mathrm{F}+\mathrm{M}=$ locator + volumetric uncertainty + datum flatness) regarding mean value and standard deviation. A total of 100,000 runs of Monte Carlo simulation were carried out. The volumetric uncertainty of the machine tool affects only the flatness, because cutting parameters were not taken into account; while the deviations in the positioning of the locators and the geometric deviations of the datum influence the angle. The obtained results are aligned with what really happens. In fact, the flatness indicates the dispersion of the surface points around the least squares plane that has an orientation different from the nominal, and the flatness depends by the volumetric uncertainty of the machine tool, while the least squares plane orientation depends on the locator positions and datum surface deviations. These considerations are the same for cases 1 and 2 . 


\subsection{Contour Milling}

The model was applied to a contouring process by removing $30 \mathrm{~mm}$ along the $Y$-axis, as shown in Figure 6a, through three passes. The same mill as the previous case was used. At the end, the angle between the planes of the machined shoulder was evaluated as a function of the two considered sources of uncertainties and their combinations (see Figure 6 b). A total of 100,000 simulation runs was considered for each considered condition characterized by one or more sources of uncertainties. The obtained results show that the deviations in locators' positions and the machine tool uncertainty affect the dispersions of the results around the mean value of $90^{\circ}$ (see Table 1).

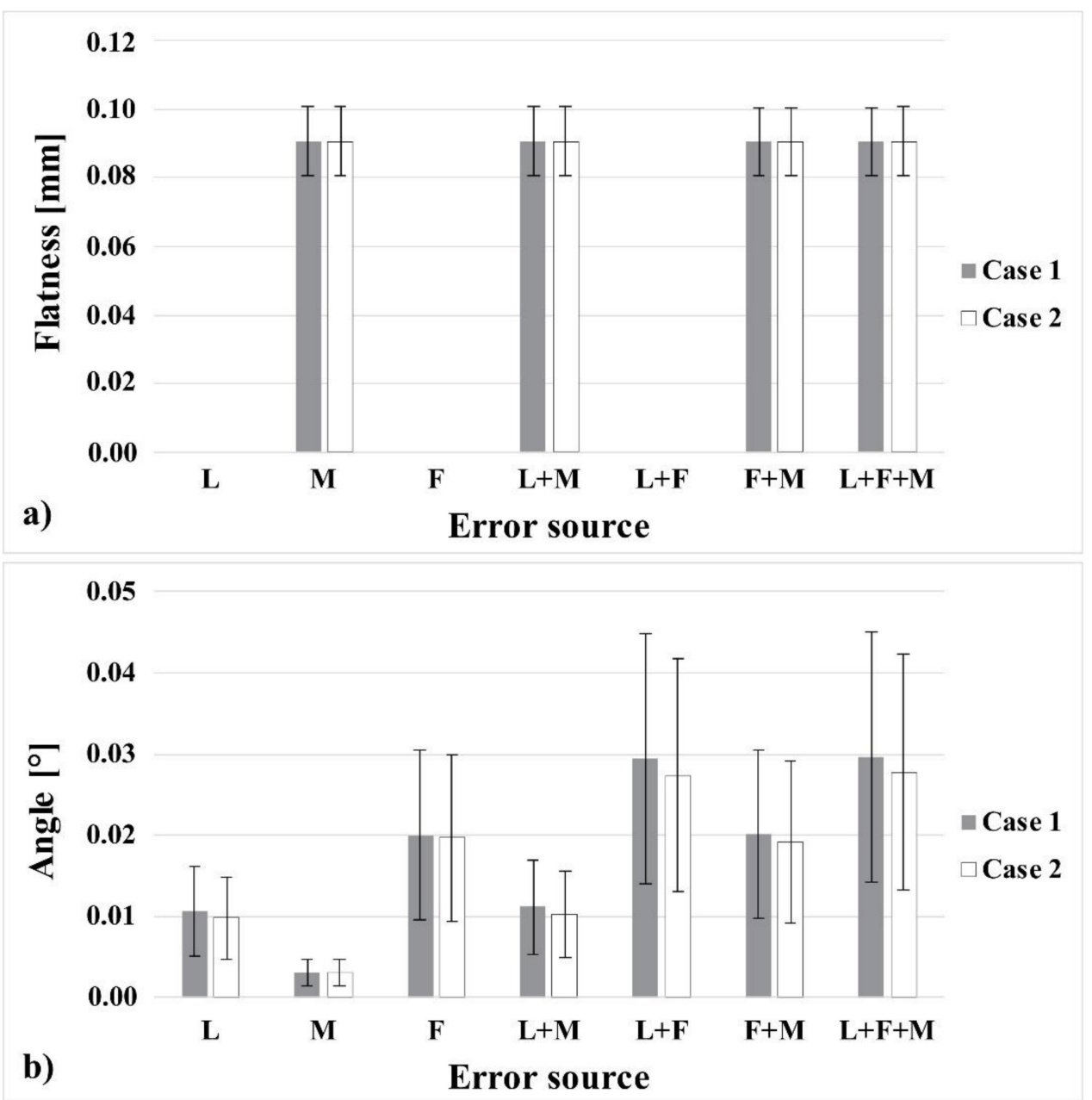

Figure 5. Results for the first (case 1) and second (case 2) configuration of the locators: (a) Flatness, (b) angle ( $\mathrm{L}=$ locator uncertainty, $\mathrm{M}=$ volumetric uncertainty of machine tool, $\mathrm{F}=$ datum flatness, $\mathrm{L}+\mathrm{M}=$ locator + volumetric uncertainty, $\mathrm{L}+\mathrm{F}=$ locator + datum flatness, $\mathrm{F}+\mathrm{M}=$ datum flatness + volumetric uncertainty, $\mathrm{L}+\mathrm{F}+\mathrm{M}=$ locator + volumetric uncertainty + datum flatness). 


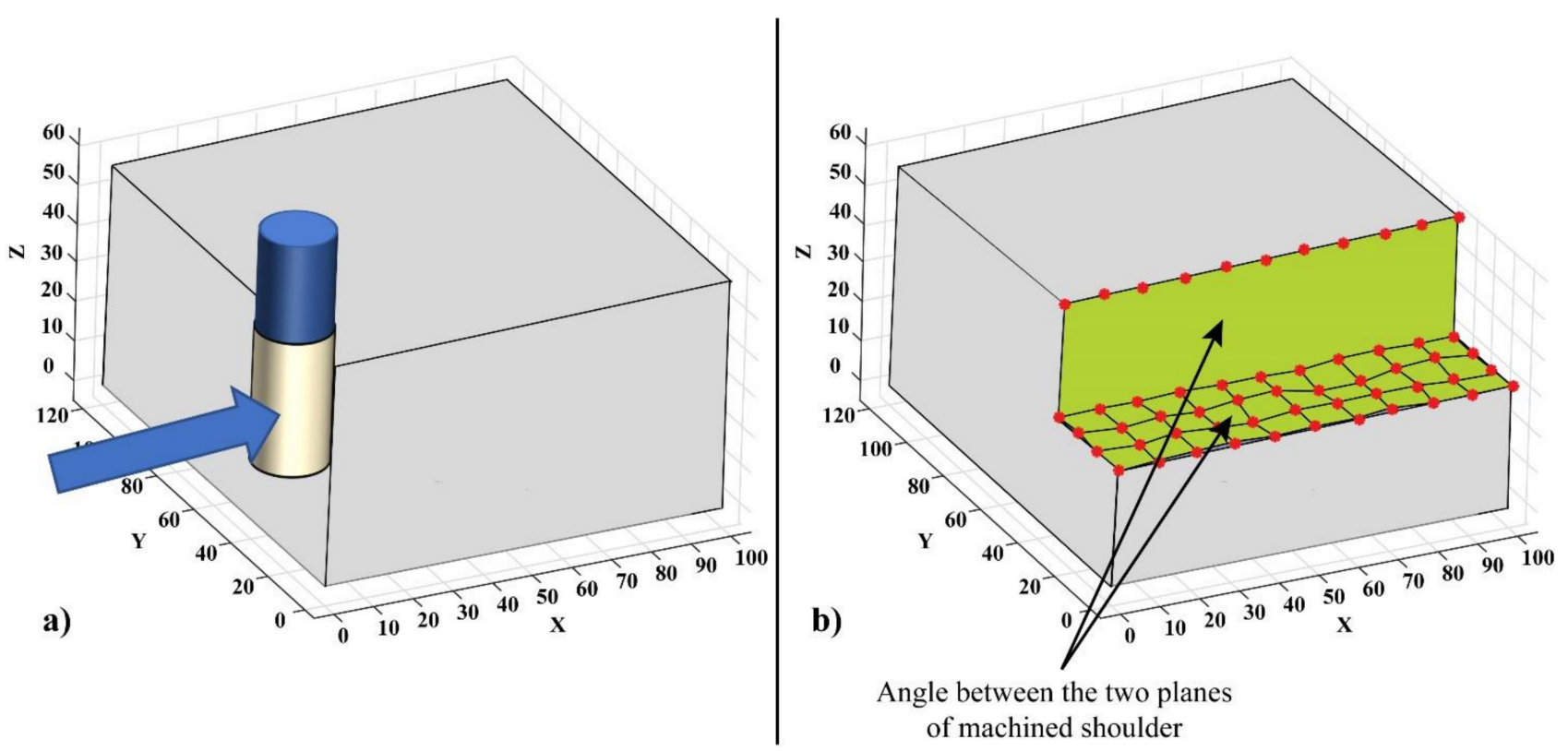

Figure 6. (a) Contouring process and (b) angle between the two planes of the machined shoulder.

Table 1. Results of contour milling.

\begin{tabular}{ccc}
\hline & Angle between the Two Planes of the Machined Shoulder \\
\hline Uncertainty Source & Mean Value $\left(^{\circ}\right)$ & Standard Deviation $\left(^{\circ}\right)$ \\
\hline Locator uncertainty & 90.00 & 0.04 \\
Volumetric uncertainty of machine tool & 90.00 & 0.02 \\
Datum flatness & 90.00 & 0.00 \\
Locator uncertainty + Volumetric & 90.00 & 0.02 \\
uncertainty & 90.00 & 0.04 \\
Locator + Datum flatness & 90.00 & 0.02 \\
Volumetric uncertainty + Datum flatness & 90.00 & 0.02 \\
Locator deviation + Volumetric & & \\
uncertainty + Datum flatness & &
\end{tabular}

In this case, a further positioning of the locators was also taken into account, as shown in Figure $2 b$. The results are the same as previously described.

\subsection{Drilling}

The plate was drilled at the nominal position $\mathrm{P}_{0}=\left[\begin{array}{ll}40,70, & 0\end{array}\right]$ and the length of the drill was $60 \mathrm{~mm}$. A drill with a diameter equal to the hole diameter was used. The considered performance indicator was the fraction of conforming parts generated by a specific locator configuration, i.e., the fraction of parts for which both of the following inequalities hold:

$$
\begin{aligned}
& d_{1} \leq t / 2 \\
& d_{2} \leq t / 2
\end{aligned}
$$

where $t$ is the location tolerance value equal to $0.2 \mathrm{~mm}$.

The conforming fraction was evaluated three times for each experimental condition and for each evaluation, 100,000 workpieces were simulated. Table 2 reports the numerical results. As shown in Table 2, the fraction of conforming parts is affected by only one of the two investigated uncertainty sources, i.e., the datum flatness. This is probably due to the small deviations of the six locators and of the machine volumetric uncertainty, which are taken by industrial values anyway. The datum flatness more significantly affects the reduction of conforming parts, since it involves contact between the datum and the locators on peaks or valleys of the datum surface, thus causing a roto-translation of the 
part. The fraction of conforming parts is significantly reduced when two or three sources of uncertainty act simultaneously, how it should be in reality, and the greater reductions are connected to the presence of the datum flatness inside the interaction. The percentage of the conforming fraction of case 2 appears greater than that in case 1, which is probably due to a more stable configuration of the locators $[39,40]$.

Table 2. Results of one drilled hole.

\begin{tabular}{ccc}
\hline Uncertainty Source & $\begin{array}{c}\text { Conforming Fraction } \\
\text { for Case 1 (\%) }\end{array}$ & $\begin{array}{c}\text { Conforming Fraction for } \\
\text { Case 2 (\%) }\end{array}$ \\
\hline Locator uncertainty & 99.99 & 99.99 \\
Volumetric uncertainty of machine tool & 99.48 & 99.48 \\
Datum flatness & 79.78 & 90.11 \\
Locator uncertainty + Volumetric uncertainty & 99.14 & 95.63 \\
Locator + Datum flatness & 75.89 & 83.49 \\
Volumetric uncertainty + Datum flatness & 39.15 & 46.68 \\
Locator deviation + Volumetric uncertainty + Datum flatness & 31.48 & 36.28 \\
\hline
\end{tabular}

\section{Conclusions}

This work presents a kinematic model to simulate the effect of two sources of uncertainty, the localization and the machine ones, on the geometrical deviation of a surface manufactured by face milling, contouring or drilling processes. The model consists of four steps. The first one evaluates the influence of the deviations in the locator positions on the workpiece reference frame. The second one estimates the deviations in the workpiece reference frame as a function of the form deviations in the workpiece datum surfaces. The third one defines the volumetric uncertainty of the machine tool. Finally, the four steps combine the three deviations. A chain of coordinate transfers from a datum reference system to another is the heart of this work, with the results being evidently right. It overcomes the literature because it considers two uncertainty sources together, such as the locator position deviations, the datum deviations and the volumetric uncertainty of the machine tool, in a simple and effective model.

The proposed kinematic model was applied to a plate that is located through 3-2-1 locators, it had a flatness deviation on its datum surfaces in contact with the locators and the volumetric uncertainty of the used machine tool was known. In this way, it was possible to estimate numerically the geometrical deviations of the milled and drilled surface by saving time, energy and materials because experimental tests have been avoided. In particular, the flatness and orientation deviation from nominal were investigated for a milled surface and the orientation deviation of a drilled hole was analyzed. From the results, it is clear how the proposed model easily allows us to estimate the deviation of a milled or a drilled surface due to the combined effect of two uncertainty sources. The proposed model allows us to take into account geometrical deviations of the part datum surfaces of $0.001 \mathrm{~mm}$, location deviations in the locators of $\pm 0.03 \mathrm{~mm}$ and machine tool positional and rotational uncertainties of $0.01 \mathrm{~mm}$ and $\sigma_{d}=0.01 * \frac{\pi}{180} \mathrm{~mm}$, respectively.

The proposed model is kinematic and it is based on the results sought in the kinematics of robots that are validated in the literature. The idea of the model is simple enough to be evidently right, since it is based on the transfer of coordinates from a datum reference system to another. The innovative ideas are the terms of the uncertainty transfer, i.e., the locator uncertainty, the workpiece datum uncertainty and the machine tool volumetric uncertainty, that are considered together inside a simple and effective model. However, experimental work to set the parameters of each considered contribution to hole or milled plane deviation is matter for further studies.

The time required by the kinematic model to simulate the two sources of uncertainty in milling or drilling was very short (a few seconds) by using a computer with an Intel core i7 950 processor running at $3.07 \mathrm{GHz}$, with $16 \mathrm{~GB}$ of RAM, a mechanical hard drive of 1TB at $5400 \mathrm{rpm}$ and running Windows 7 Professional. The required time is so short that it is compatible with online data processing. 
Further elements influencing the geometrical deviations of the manufactured surface, such as those connected with the process uncertainty, may be added in a subsequent development of the model. It is a subject of further research.

Author Contributions: Conceptualization, W.P.; methodology, W.P.; software, A.C.; validation, W.P. and A.C.; data curation, A.C. and W.P.; writing—original draft preparation, W.P.; writing—review and editing, A.C. All authors have read and agreed to the published version of the manuscript.

Funding: This research received no external funding.

Institutional Review Board Statement: Not applicable.

Informed Consent Statement: Not applicable.

Data Availability Statement: No data available.

Conflicts of Interest: The authors declare no conflict of interest.

\section{Abbreviations}

\begin{tabular}{|c|c|}
\hline $\mathrm{p}_{\mathbf{i}}\left(\mathrm{x}_{\mathrm{i}}, \mathrm{y}_{\mathrm{i}}, \mathrm{z}_{\mathrm{i}}\right)$ & i-th locator $(\mathrm{i}=1,2,3,4,5$ and 6$)$ \\
\hline $\mathbf{P}_{0}\left(\mathrm{x}_{0}, \mathrm{y}_{0}, \mathrm{z}_{0}\right)$ & nominal coordinates of the center of the drilled hole in RF \\
\hline $\mathbf{P}_{0}{ }^{\prime}\left(\mathrm{x}_{0}{ }^{\prime}, \mathrm{y}_{0}{ }^{\prime}, \mathrm{z}_{0}{ }^{\prime}\right)$ & actual coordinates of the center of the drilled hole in LRF \\
\hline $\mathbf{P}_{0}{ }^{\prime \prime}\left(\mathrm{x}_{0}{ }^{\prime}, \mathrm{y}_{0}{ }^{\prime}, \mathrm{z}_{0}{ }^{\prime}\right)$ & actual coordinates of the center of the drilled hole in PRF \\
\hline $\mathrm{X}$ & $x$ coordinate of point in $\mathrm{RF}$ \\
\hline$X^{\prime}$ & $x$ coordinate of point in LRF \\
\hline$X^{\prime \prime}$ & $x$ coordinate of point in PRF \\
\hline Y & y coordinate of point in RF \\
\hline $\mathrm{Y}^{\prime}$ & y coordinate of point in LRF \\
\hline$Y^{\prime \prime}$ & y coordinate of point in PRF \\
\hline Z & $\mathrm{z}$ coordinate of point in RF \\
\hline$Z^{\prime}$ & $\mathrm{z}$ coordinate of point in LRF \\
\hline$Z^{\prime \prime}$ & $\mathrm{z}$ coordinate of point in PRF \\
\hline RF & nominal reference frame \\
\hline LRF & locator reference frame \\
\hline PRF & part reference frame \\
\hline${ }^{0} \mathbf{R}_{\mathrm{p}}^{-1}$ & homogeneous transformation matrix from RF to LRF \\
\hline${ }^{1} \mathbf{R}_{\mathbf{p}}^{-2}$ & homogeneous transformation matrix from LRF to PRF \\
\hline $\mathbf{R}$ & rotational matrix from RF to LRF \\
\hline $\mathbf{R}^{\prime}$ & rotational matrix from LRF to PRF \\
\hline $\mathbf{t}_{\mathbf{0}}$ & vector describing the RF origin position referred to the LRF \\
\hline $\mathbf{t}_{0}^{\prime}$ & vector describing the LRF origin position referred to the PRF \\
\hline $\mathbf{o}^{\mathrm{T}}$ & a zero vector $[3 \times 1]$ \\
\hline $\mathbf{v}_{\mathbf{i}}$ & normal vector i-th in RF \\
\hline $\mathbf{v}_{\mathbf{i}}^{\prime}$ & i-th normal vector in LRF \\
\hline $\mathrm{p}_{\mathrm{ij}}$ & vector joining point $\mathbf{P}_{\mathbf{i}}$ and $\mathbf{P}_{\mathbf{j}}$ \\
\hline$n_{i}$ & i-th normal vector normalized in RF \\
\hline $\mathbf{n}_{\mathbf{i}}^{\prime}$ & i-th normal vector normalized in LRF \\
\hline $\mathbf{n}_{i}^{T}$ & i-th normal vector normalized and transposed in RF \\
\hline $\mathbf{n})_{i}^{T}$ & i-th normal vector normalized and transposed in LRF \\
\hline I & identity matrix \\
\hline$\rho$ & spatial autoregressive parameter \\
\hline W & neighborhood matrix \\
\hline$\epsilon$ & white noise \\
\hline$\Delta p$ & position error of the drill tip in the machine tool reference system \\
\hline$\Delta d$ & direction error of the tool axis \\
\hline $\mathrm{k}$ & homogeneous vector \\
\hline$\varepsilon_{i}(\mathrm{j})$ & the rotational error around the $i$ axis due to a translation along the $j$ axis \\
\hline$\delta_{i}(\mathrm{j})$ & the translation error along the $i$ axis due to a translation along the $j$ axis. \\
\hline
\end{tabular}




\section{References}

1. Benardos, P.G.; Vosniakos, G.-C. Predicting surface roughness in machining: A review. Int. J. Mach. Tools Manuf. 2003, 43, 833-844. [CrossRef]

2. Denkena, B.; Böß, V.; Nespor, D.; Gilge, P.; Hohenstein, S.; Seume, J. Prediction of the 3D Surface Topography after Ball End Milling and its Influence on Aerodynamics. Proc. CIRP 2015, 31, 221-227. [CrossRef]

3. ISO 4287:1997. Geometrical Product Specification (GPS)-Surface Texture: Profile Method-Terms, Definitions and Surface Texture Parameters, 1st ed.; ISO: Geneva, France, 2009; pp. 1-25.

4. Astakhov, V.P. Surface Integrity-Definition and Importance in Functional Performance. In Surface Integrity in Machining, 1st ed.; Springer: London, UK, 2010; Volume 1, pp. 1-35.

5. Zmarzły, P. Technological Heredity of the Turning Process. Techn. Gaz. 2020, 27, 11-25.

6. Slocum, A. Precision Machine Design, 1st ed.; Prentice Hall: Englewood Cliffs, NJ, USA, 1992.

7. Uriarte, L.; Herrero, A.; Zatarain, M.; Santiso, G.; López de Lacalle, L.N.; Lamikiz, A.; Albizuri, J. Error budget and stiffness chain assessment in a micromilling machine equipped with tools less than $0.3 \mathrm{~mm}$ in diameter. Precis. Engin. 2007, 31, 1-12. [CrossRef]

8. Pimenov, D.Y.; Guzeev, V.I.; Krolczyk, G.; Mozammel, M.; Wojciechowski, S. Modeling flatness deviation in face milling considering angular movement of the machine tool system components and tool flank wear. Precis. Eng. 2018, 54, 327-337. [CrossRef]

9. Bustillo, A.; Pimenov, D.Y.; Mozammel, M.; Wojciech, K. Machine-learning for automatic prediction of flatness deviation considering the wear of the face mill teeth. J. Intel. Manuf. 2020, in press. [CrossRef]

10. Diaz Tena, E.; Ugalde, U.; López de Lacalle, L.N.; de la Iglesia, A.; Calleja, A.; Campa, F.J. Propagation of assembly errors in multitasking machines by the homogeneous matrix method. Int. J. Adv. Manuf. Technol. 2013, 68, 149-164. [CrossRef]

11. Los, A.; Mayer, J.R.R. Application of the adaptive Monte Carlo method in a five-axis machine tool calibration uncertainty estimation including the thermal behaviour. Precis. Eng. 2018, 53, 17-25. [CrossRef]

12. Miller, J.E.; Longstaff, A.P.; Parkinson, S.; Fletcher, S. Improved machine tool linear axis calibration through continuous motion data capture. Precis. Eng. 2017, 47, 249-260. [CrossRef]

13. Yang, J.; Ding, H. A new position independent geometric errors identification model of five-axis serial machine tools based on differential motion matrices. Int. J. Mach. Tools Manuf. 2016, 104, 68-77. [CrossRef]

14. Fu, G.; Fu, J.; Xu, Y.; Chen, Z.; Lai, J. Accuracy enhancement of five-axis machine tool based on differential motion matrix: Geometric error modeling, identification and compensation. Int. J. Mach. Tools Manuf. 2015, 89, 170-181. [CrossRef]

15. Rong, Y.; Zhu, Y. Computer-Aided Fixture Design: Manufacturing Engineering and Materials Processing, 1st ed.; Marcel Dekker Inc.: New York, NY, USA, 1999.

16. Villeneuve, F.; Legoff, O.; Bourdet, P. Three Dimensional geometrical tolerancing in process planning. CIRP J. Manuf. Sys. 2000, 30, 20-39.

17. Clement, A.; Bourdet, P. A study of optimal-criteria identification based on the small-displacement screw model. CIRP Ann. Manuf. Technol. 1988, 37, 503-506.

18. Choudhuri, S.A.; De Meter, E.C. Tolerance Analysis of Machining Fixture Locators. J. Manuf. Sci. Eng. 1999, 121, $273-281$. [CrossRef]

19. Wang, M.Y.; Pelinescu, D. Optimizing fixture layout in a point-set domain. IEEE Trans. Robot. 2001, 17, 312-323. [CrossRef]

20. Weill, R.; Darel, I.; Laloum, M. The influence of fixture positioning errors on the geometric accuracy of mechanical parts. In Proceedings of the CIRP Conference on Production Engineering and Manufacturing Science, Tianjin, China, 12-14 September 1991; pp. 215-225.

21. Wang, L.; Duan, F.; Liang, C. A global optimal algorithm for camera calibration with one-dimensional objects. In Human-Computer Interaction. Design and Development Approaches, Proceedings of the 14th International Conference, Orlando, FL, USA, 9-14 July 2011; Jacko, J., Ed.; Springer: Berlin, Germany, 2011; p. 6761.

22. Ferreira, P.M.; Liu, C.R.; Merchant, E. A contribution to the analysis and compensation of the geometric error of a machining center. CIRP Ann. Manuf. Technol. 1986, 35, 259-262. [CrossRef]

23. Tian, W.; Gao, W.; Zhang, D.; Huang, T. A general approach for error modeling of machine tools. Int. J. Mach. Tools Manuf. 2014, 79, 17-23. [CrossRef]

24. Chen, J.X.; Lin, S.W.; Zhou, X.L. A comprehensive error analysis for the geometric error of a multi-axis machine tool. Int. J. Mach. Tools Manuf. 2016, 106, 56-66. [CrossRef]

25. Tang, H.; Duan, J.A.; Lan, S.; Shui, H. A new geometric error modelling approach for multi-axis system based on stream of variation theory. Int. J. Mach. Tools Manuf. 2015, 92, 41-51. [CrossRef]

26. Olvera, D.; López de Lacalle, L.N.; Compean, F.I.; Fx-Valdivielso, A.; Lamikiz, A.; Campa, F.J. Analysis of the tool tip radial stiffness of turn-milling centers. Int. J. Adv. Manuf. Technol. 2012, 60, 883-891. [CrossRef]

27. He, Z.; Fu, J.; Zhang, X.; Shen, H. A uniform expression model for volumetric errors of machine tools. Int. J. Mach. Tools Manuf. 2016, 100, 93-104. [CrossRef]

28. Kiridena, V.; Ferreira, M.P. Computational approaches to compensating quasistatic errors of three-axis machining centers. Int. J. Mach. Tools Manuf. 1994, 34, 127-145. [CrossRef]

29. Smith, S.; Woody, B.; Miller, J. Improving the accuracy of large scale monolithic parts using fiducials. CIRP Ann. Manuf. Technol. 2005, 54, 483-486. [CrossRef] 
30. Xiang, S.; Altintas, Y. Modeling and compensation of volumetric errors for five-axis machine tools. Int. J. Mach. Tools Manuf. 2016, 101, 65-78. [CrossRef]

31. Armillotta, A.; Carrino, L.; Moroni, G.; Polini, W.; Semeraro, Q. An analytical approach to machining deviation due to fixturing. In Geometric Product Specification and Verification: Integration of Functionality, 1st ed.; Bourdet, P., Mathieu, L., Eds.; Springer: Amsterdam, The Netherlands, 2003; pp. 175-184.

32. Polini, W.; Moroni, G. Position deviation of a holes pattern due to six-point locating principle. In Models for Computer Aided Tolerancing in Design and Manufacturing, 1st ed.; Davidson, J.K., Ed.; Springer: Dordrecht, The Netherlands, 2007; Volume 1, pp. 201-211.

33. Moroni, G.; Petrò, S.; Polini, W. Robust design of fixture configuration. Proc. CIRP 2014, 21, 189-194. [CrossRef]

34. Corrado, A.; Polini, W. Manufacturing signature in jacobian and torsor models for tolerance analysis of rigid parts. Robot. Comput. Integr. Manuf. 2017, 46, 15-24. [CrossRef]

35. Corrado, A.; Polini, W. Manufacturing signature in variational and vector-loop models for tolerance analysis of rigid parts. Int. J. Adv. Manuf. Technol. 2017, 88, 2153-2161. [CrossRef]

36. Corrado, A.; Polini, W.; Moroni, G. Manufacturing signature and operating conditions in a variational model for tolerance analysis of rigid assemblies. Res. Eng. Des. 2017, 28, 529-544. [CrossRef]

37. Kazar, B.M.; Celik, M. Spatial AutoRegression (SAR) Model; Springer: Boston, MA, USA, 2012.

38. Siciliano, B.; Sciavicco, L.; Villani, L.; Oriolo, G. Robotics: Modelling, Planning and Control; Springer: London, UK, 2008.

39. Polini, W.; Corrado, A. A general model to estimate hole location deviation in drilling: The contribution of three error sources. Int. J. Adv. Manuf. Technol. 2019, 102, 545-557. [CrossRef]

40. Polini, W.; Corrado, A. A kinematic approach for error modelling in drilling. Eng. Comput. 2019, 36, 1364-1383. [CrossRef] 